\title{
Application of Kalman filter in power plant
}

\author{
Yiwen $\mathrm{Xiao}^{1, \mathrm{a}}$, Jiangwen $\mathrm{Xiao}^{1}$,Jing $\mathrm{Wu}^{2}{ }^{2}{\mathrm{Jun} \mathrm{Li}^{1}, \text {,Chun } \mathrm{Chen}}^{1}$ \\ ${ }^{1}$ School of Automation, Huazhong University of Science and Technology, Wuhan,China \\ ${ }^{2}$ Jiangnan University in Wuxi,Jiangsu Prov,China \\ ayiwenxiao2015@hust.edu.cn
}

Keywords: Kalman Filter; Transformer substation; Temperature warning;

Abstract. In substation temperature monitoring system. For general detection system, when the temperature has reached a dangerous temperature alarm will occur, but in this case the situation is very dangerous. Not only affect the power supply, is more likely to life and property losses,. So before reaching dangerous temperatures, it is necessary to predict this situation. Based on the Kalman filter temperature substation to predict temperature of electrical components timely , warning of danger and take appropriate measures to prevent the risk of accidents.

\section{Introduction}

Currently, the workload of patrol network is especially large. And the quality of patrol do not meet the substation inspection requirements. Because errors that staff inspection records inevitably exist, so the use of sensors to monitor temperature recorded in real time is necessary .

The temperature detection system not only to record temperature, but also to forecast temperature. Kalman filter is a recursive linear minimum variance estimation technique, it used recursive form, Based on the measured value of the current time, we can get recursive state estimation value of the current time. The Kalman filter (Kalman, 1960), which is based on a dynamic causal model of the plant, is able to effectively cope with highly dynamic regimes[1], Due to the observed data involve in the impact of system noise and interference, so the optimal estimation can also be seen as a filtering process. The theory has a small amount of calculation, and high running speed, etc. So it has been an effective algorithm for tracking dynamic processes for over four decades[2,3,4].

\section{Kalman filtering theory}

Kalman filter is an optimal recursive data processing algorithm. After nearly 40 years of development, it also used in various fields, including robotics navigation, control, sensor data fusion even in military radar systems and missile tracking. In recent years, even it has been used in computer image processing, such as head and face recognition, image segmentation, image edge detection.

1. Mathematical model of one dimensional time varying random signals

The state of $\mathrm{k}$ random signal recorded at the time of $\mathrm{x}(\mathrm{k})$, for each state to determine $\mathrm{k}$, has a certain random signal $\mathrm{x}(\mathrm{k})$. Different time status, then you can get a sequence $\{\mathrm{x}(\mathrm{k})\}$. Consider a dynamic process (or target) with a linear time-varying model[5].

$$
\mathrm{x}(\mathrm{k})=\mathrm{Ax}(\mathrm{k}-1)+\mathrm{Bu}(\mathrm{k})+\mathrm{w}(\mathrm{k})
$$


Formula (1), $\mathrm{x}(\mathrm{k})$ is the amount of system state at time $\mathrm{k}, \mathrm{x}(\mathrm{k}-1)$ is a system state quantity of time $\mathrm{k}-1, \mathrm{u}(\mathrm{k})$ is the amount of control of the system in $\mathrm{k}$ times, A and B are a coefficient of the system. w(k) is a white Gaussian noise of $\mathrm{k}$ moment, characterized by its digital

Means: $\mathrm{E}[\mathrm{w}(\mathrm{k})]=0$

Variance: $\mathrm{E}[\mathrm{w}(\mathrm{k})]^{2}=\delta_{6}^{2}$

Autocorrelation sequence: $\mathbb{E}[w(k) w(j)]=\left\{\begin{array}{cc}\delta_{u}^{2} & k=j \\ 0 & k \neq j\end{array}\right.$

2. Mathematical model of signal measurements

At the output of the $\mathrm{K}$ moment, we must know the measurement value of the $\mathrm{K}$ sensor, then we can estimate the true value of the $\mathrm{K}$ time. The mathematical model of the signal measuring value is expressed by the following equation

$$
z(k)=H x(k)+v(k)
$$

In the formula, $\mathrm{z}(\mathrm{k})$ is a measure of $\mathrm{k}$ time, $\mathrm{v}(\mathrm{k})$ represents the measurement process of the Gauss white noise, $\mathrm{H}$ is the parameters of the measurement system.

3. Kalman filter algorithm

In this algorithm, we first need to know the output value of the state of the present time, and the mathematical expressions are as follows

$$
x(k \mid k-1)=A x(k-1 \mid k-1)+B u(k)
$$

$\mathrm{x}(\mathrm{k} \mid \mathrm{k}-1)$ is a state predicted by previous state, $\mathrm{x}(\mathrm{k}-1 \mid \mathrm{k}-1)$ is a optimal result in $\mathrm{k}-1, \mathrm{u}(\mathrm{k})$ is the present state of the control quantity (may 0).

Using (3) to update system results, but the corresponding covariance has not been updated, the updated formula is

$$
\mathrm{p}(\mathrm{k} \mid \mathrm{k}-1)=A \mathrm{p}(\mathrm{k}-1 \mid \mathrm{k}-1) A^{T}+Q
$$

$\mathrm{p}(\mathrm{k} \mid \mathrm{k}-1)$ is $\mathrm{x}(\mathrm{k} \mid \mathrm{k}-1)$ corresponding covariance, $\mathrm{p}(\mathrm{k}-1 \mid \mathrm{k}-1)$ is $\mathrm{x}(\mathrm{k}-1 \mid \mathrm{k}-1)$ corresponding covariance, $\mathrm{A}^{\mathrm{T}}$ is a transposed matrix , $\mathrm{Q}$ is the covariance of system procedures.

(3) and (4) is the predicted value of the system, combined with the predicted values to the current collection system, the calculation formula for the optimal estimate.

$\mathrm{x}(\mathrm{k} \mid \mathrm{k})=\mathrm{Ax}(\mathrm{k} \mid \mathrm{k}-1)+\mathrm{kg}(\mathrm{k})(z(k)-H x(k \mid k-1))$

$\mathrm{x}(\mathrm{k} \mid \mathrm{k})$ is the best estimate values in $\mathrm{k}$ state where $\mathrm{kg}$ (kalman gain) is the Kalman gain:

$$
\operatorname{kg}(k)=\frac{p(k \mid k-1) H^{T}}{H p(k \mid k-1) H^{T}+R}
$$


(3), (4), (5), (6) can calculate the optimal state estimate $\mathrm{k}$ moment, in order to calculate the optimal state estimate $\mathrm{k}+1$ time, you need to calculate the optimal estimation value $\mathrm{x}(\mathrm{k} \mid \mathrm{k})$ corresponding covariance $\mathrm{p}(\mathrm{k} \mid \mathrm{k})$ :

$$
\mathrm{p}(\mathrm{k} \mid \mathrm{k})=(\mathrm{I}-\mathrm{kg}(\mathrm{k}) \mathrm{H}) p(k \mid k-1)
$$

Where $\mathrm{I}$ is the identity matrix, as to a single measurement for a single model, $\mathrm{I}=1$. When the system enters the state $k+1, p(k \mid k)$ is the equation (4) $p(k-1 \mid k-1)$. According to the above five formula, the temperature can be predicted from the regression calculation.

By the formula (5) can constitute an optimal recursive estimator. The diagram is shown below:

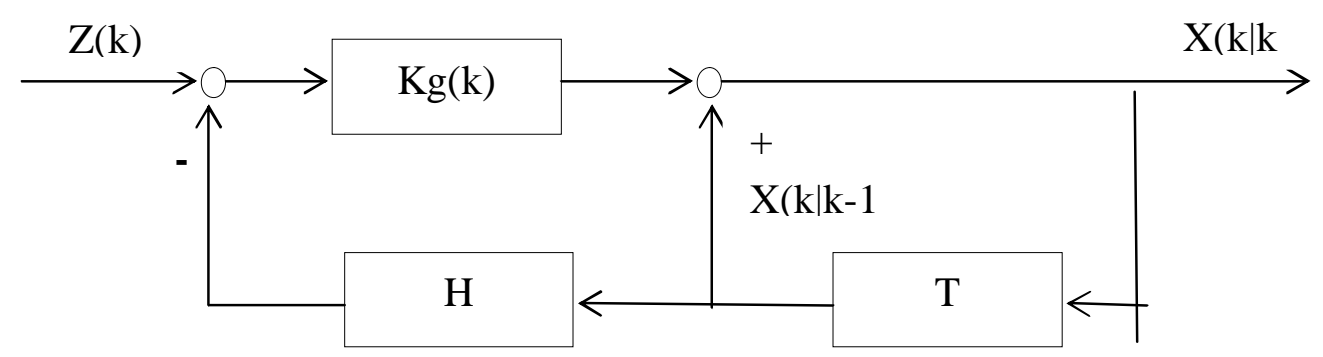

Fig.1 The diagram of Kalman filter

Formula (3), (4), (5), (6), (7) are five basic formulas for Kalman filter theory, according to the five formulas to calculate the previous state, then use measure value of current time to estimate the real values of current time, and ultimately to eliminate the noise, aim to reduce the errors.

\section{Application of Kalman Filtering}

In process of temperature warning, the Kalman filter's role is very significant[6]. In the application of substation, estimating current time according to the previous values, then collected the temperature from temperature sensor, to calculate the optimal estimate of the current state of the Kalman filter theory. The algorithm flowchart is shown below.

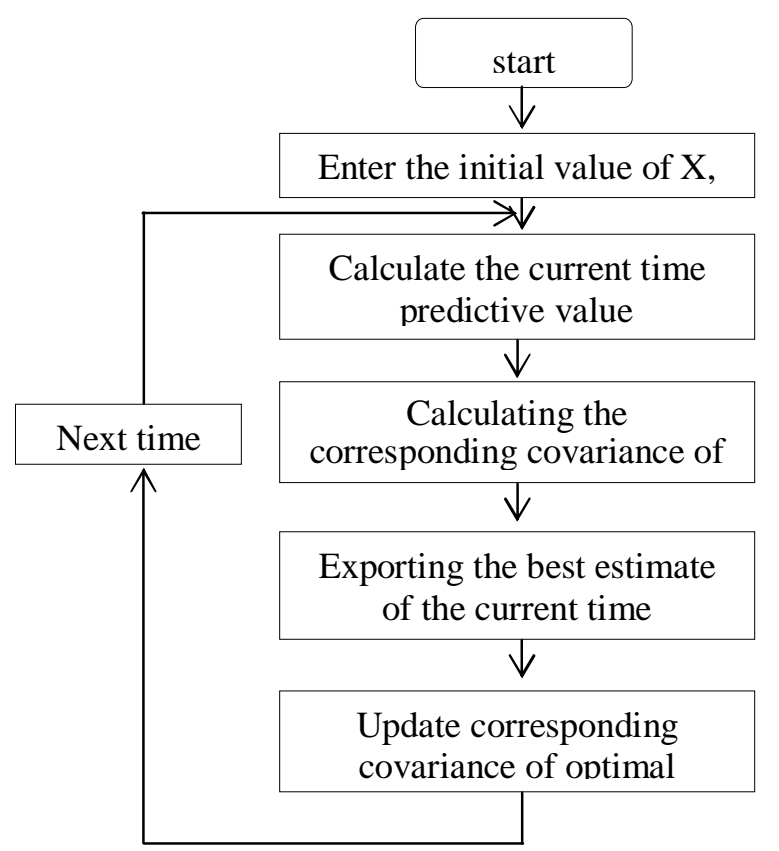

Fig.2 kalman filtering algorithm flow chart 
Below will be in a simplified environment for kalman filter simulation. It is assumed that the temperature of a component is constant, which makes the system coefficient $A=I$, the current state control of $U(k)=0$, and the coefficient $H$ of the system is $I$, and the random function of MATLAB is introduced into Gauss random white noise.

The following figure are simulation diagrams when $\mathrm{D}=30,50,80,100$ :

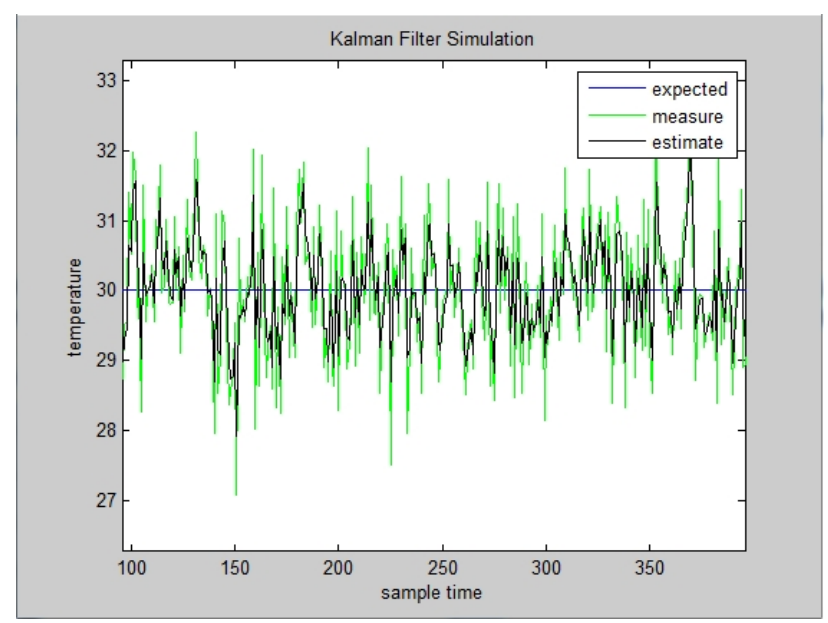

$\mathrm{D}=30$

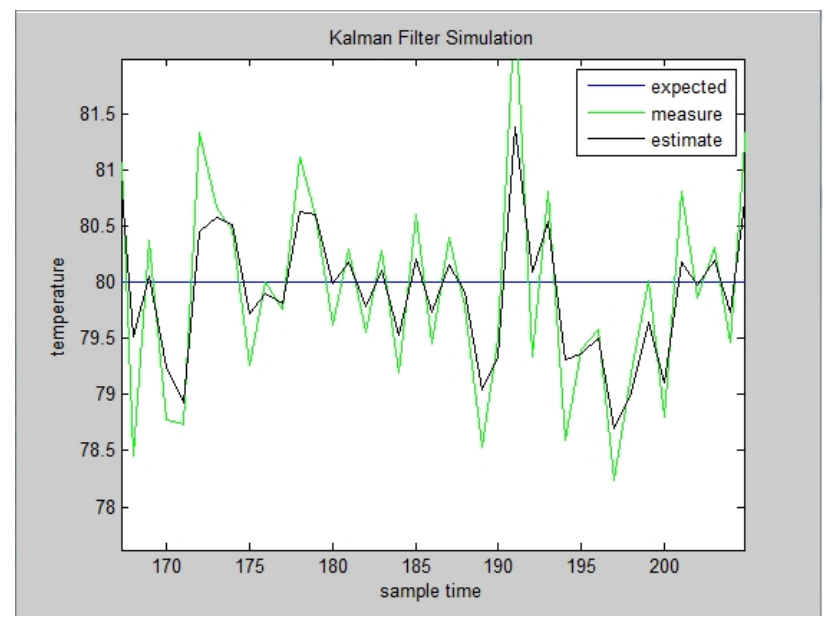

$\mathrm{D}=80$

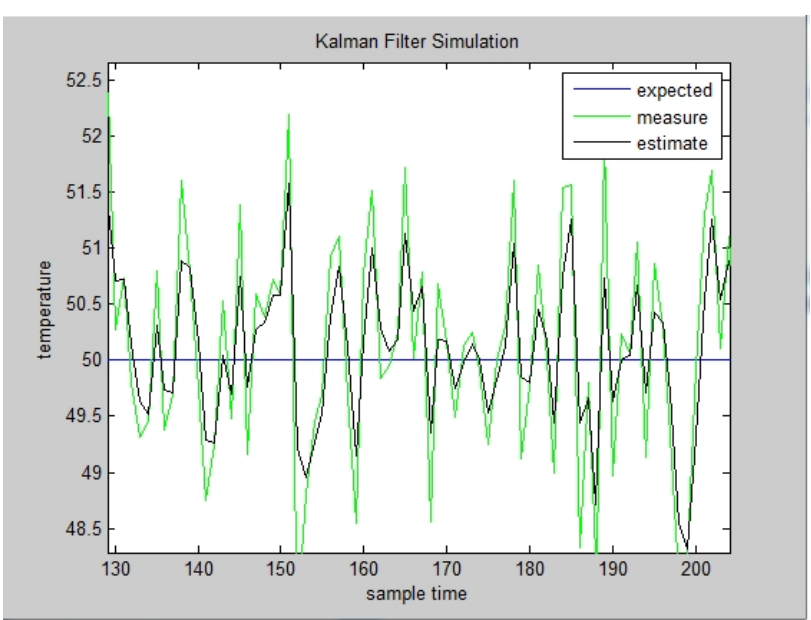

$\mathrm{D}=50$

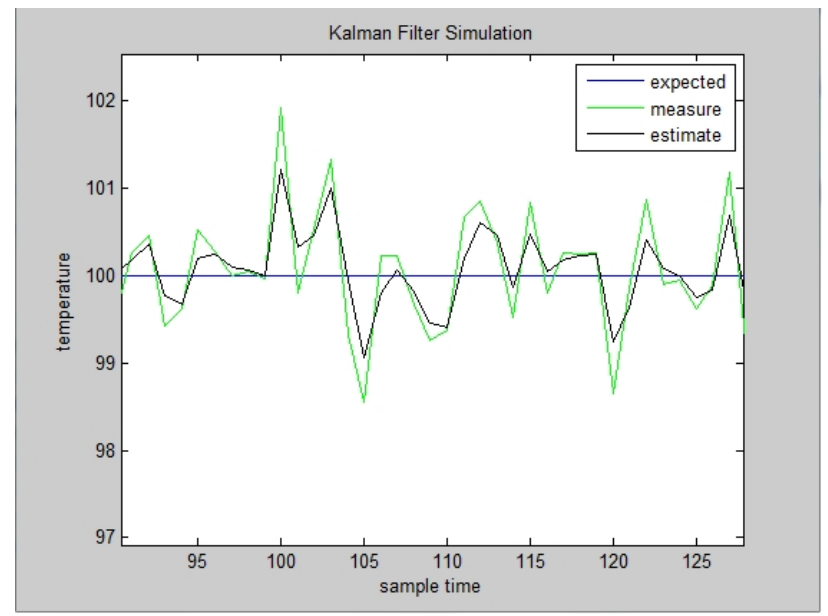

$\mathrm{D}=100$

Fig.3 kalman filter simulation

From the simulation charts above, the error which from sensor is large, the effect of noise is obvious. The temperature curve of the kalman filter is relatively smooth, and the fluctuation is relatively small. On the basis of the temperature sensor measurements, the result is improve. The filtering value will get more relation with measurement value, so the problem of the divergence of the filter can be solve deficiently[7]. But compared to the actual temperature value, there exist error. From four pictures above, both high and low temperature, the degree of improvement in the output of the Kalman filter is fairly[8].

\section{Conclusion}

This paper describes the kalman filter, and its application in substation temperature. There are some conclusions can be seen from the simulation results, the kalman filter in temperature prediction does have a significant effect, but the effect is limited, due to the the algorithm is simple, efficient, and therefore in practice has been widely used, not only make a great contribution to scientific research, but also to our lives. 


\section{References}

[1] Amir Vasebi, Éric Poulin, Daniel Hodouin, Determining a dynamic model for flotation circuits using plant data to implement a Kalman filter for data reconciliation, J. Control Engineering Practice 46 (2016) 37-50.

[2] A. E. Bryson, Y. C. Ho. Applied Optimal Control: Optimization, Estimation, and Control. Hemisphere, New York, 1975.

[3] B. D. O. Anderson, J. B. Moore. Optimal Filtering. Prentice-Hall. Englewood Cliffs. NJ., 1979.

[4] Y. Bar-Shalom, T. E. Fortmann. Tracking and Data Association. Academic Press, 1988.

[5] Reza Olfati-Saber, Kalman-Consensus Filter : Optimality, Stability, and Performance,C. Joint 48th IEEE Conference on Decision and Control and 28th Chinese Control Conference, Shanghai, P.R. China,2009,pp.7036-7042.

[6] Cassola F, Burlando M. Wind speed and wind energy forecast through Kalman filtering of Numerical Weather Prediction model output[J]. Applied Energy, 2012, 99(6):154-166.

[7] Li Yang, Hu Baiqing. Research on Integrated Navigation Algorithm Based on Improved Fading-memory Filter.Computer Simulation, 2012; 29(3): 117-119.

[8] Zhao Y. Performance evaluation of Cubature Kalman filter in a GPS/IMU tightly-coupled navigation system[J]. Signal Processing, 2015, 119:67-79. 